\title{
Passivating boron silicate glasses for co-diffused high-efficiency n-type silicon solar cell application
}

\author{
Josh Engelhardt, ${ }^{\text {a) }}$ Alexander Frey, Sebastian Gloger, Giso Hahn, and Barbara Terheiden \\ Department of Physics, University of Konstanz, 78457 Konstanz, Germany
}

(Received 11 June 2015; accepted 20 July 2015; published online 28 July 2015)

\begin{abstract}
Doping layers commonly have but one function: supplying the dopants to form a doped region within a substrate. This work presents B doping layers/stacks, which at the same time supply dopant atoms, passivate the B-doped crystalline Si surface sufficiently well $\left(\mathrm{j}_{\mathrm{OE}}<50 \mathrm{fA} / \mathrm{cm}^{2}\right)$, and show optical properties suitable for anti-reflective coating. Furthermore, these boron silicate glasses can act as a barrier against parasitic $\mathrm{P}$ in-diffusion during a co-diffusion step. The boron emitters diffused from the inductively coupled plasma plasma-enhanced chemical vapor-deposited B containing $\mathrm{SiO}_{\mathrm{x}}$ layers are investigated and optimized concerning passivation quality and contact properties for high-efficiency n-type solar $\mathrm{Si}$ cell designs. It is shown that even $10 \mathrm{~nm}$ thin $\mathrm{SiO}_{\mathrm{x}}: \mathrm{B}$ films already allow for suitable emitter sheet resistance for screen-printed contacts. Furthermore, $\mathrm{SiO}_{\mathrm{x}}: \mathrm{B}$ layers presented here allow for $\mathrm{iV}_{\mathrm{OC}}$ values of $675 \mathrm{mV}$ and contact resistivity of $1 \mathrm{~m} \Omega \mathrm{cm}^{2}$ for commercial $\mathrm{Ag}$ instead of $\mathrm{Ag} / \mathrm{Al}$ pastes on the diffused boron emitter passivated with the $\mathrm{SiO}_{\mathrm{x}}$ : $\mathrm{B}$ layer supporting the contact formation. All of these properties can be achieved within one single B doping layer/stack. @ 2015 AIP Publishing LLC. [http://dx.doi.org/10.1063/1.4927667]
\end{abstract}

B doped emitters ${ }^{1}$ are commonly used in n-type crystalline $\mathrm{Si}$ solar cell concepts. Aside from commonly used gasphase diffusions using $\mathrm{BBr}_{3}^{2,3}$ or $\mathrm{BCl}_{3}{ }^{4}$ sources, chemical vapor deposited (CVD) doping layers can be used to form the necessary diffusion source. ${ }^{5-10}$ Using plasma-enhanced chemical vapor deposited (PECVD) doping layers ${ }^{5-10}$ reduces the number of solar cell process steps compared to gas phase based processes and increases the flexibility of future industrial process flows for advanced cell designs such as n-type passivated emitter rear totally diffused (PERT) or interdigitated back contact (IBC) solar cells. ${ }^{10}$ Furthermore, PECVD doping layers allow for a larger parameter range of doping profiles because of the separation of doping source deposition and drive-in step. This approach allows for simultaneous co-diffusion of different dopants at a variety of doping levels and polarities on one Si wafer and within only one high-temperature step. The film properties and drive-in step can be engineered to yield the desired surface doping density, profile depth, and shape. While surface doping density and general shape depend largely on the doping source, profile depth is mainly, but not exclusively, controlled by drive-in step parameters. The properties of the boron silicate glasses (BSG or $\mathrm{SiO}_{\mathrm{x}}: \mathrm{B}$ ) or other deposited layers depend largely on the deposition parameters (gas, flow, etc.) and the kind of CVD deposition method. In this work, we consider only PECVD tools that commonly use $\mathrm{SiH}_{4}$, an oxidizing gas, and a doping gas (e.g., $\mathrm{B}_{2} \mathrm{H}_{6}$ as $\mathrm{B}$ source) to form dielectric doping layers such as $\mathrm{B}$ containing silicon oxides $\left(\mathrm{SiO}_{\mathrm{x}}\right.$ : $\left.\mathrm{B}\right)$ or silicon oxy-nitrides $\left(\mathrm{SiO}_{\mathrm{x}} \mathrm{N}_{\mathrm{y}}: \mathrm{B}\right)$. These layers have doping as well as barrier properties. ${ }^{6,8-10}$

CVD as well as gas-phase grown doping layers as diffusion source have not been commonly used as passivation layers, and $\mathrm{CVD} \mathrm{SiO}_{\mathrm{x}}$ doping layers have not yet been

\footnotetext{
${ }^{\text {a) }}$ Author to whom correspondence should be addressed. Electronic mail: josh.engelhardt@uni-konstanz.de. Tel.: +49 (0) 7531/88-2080.
}

reported to reach the high level of passivation and optical transmission necessary for good cell performance directly after the diffusion process without further treatment. In addition, related investigations on passivation of $\mathrm{B}$ containing $\mathrm{SiO}_{\mathrm{x}}$ layers did not show sufficiently low $\mathrm{j}_{\mathrm{OE}}$ values for B emitters (depending on sheet resistance) up to now. ${ }^{12,13}$ Therefore, B emitters on n-type Si wafers are commonly passivated after removal of the doping layer using $\mathrm{SiO}_{\mathrm{x}} / \mathrm{SiN}_{\mathrm{x}}$ or $\mathrm{Al}_{2} \mathrm{O}_{3} / \mathrm{SiN}_{\mathrm{x}}$ layer stacks in additional processing steps exploiting chemical and field effect passivation of those layers. ${ }^{11}$ Most BSG layers are only used as doping layers but not as multi-purpose layers. In the following, we will show that it is also possible and very effective to optimize BSG layers for multiple purposes. This opens different possibilities for, e.g., the development of more cost-effective solar cell designs.

For contacting $\mathrm{B}$ emitters on n-type Si wafers, $\mathrm{Ag} / \mathrm{Al}$ paste is commonly screen-printed and fired leading to a sufficiently low contact resistivity between metal contact and semiconductor. However, $\mathrm{Ag} / \mathrm{Al}$ pastes have the drawback of $\mathrm{Al}$ spiking into the $\mathrm{B}$ emitter and possibly damaging the space charge region. Until now, it was not possible to reach the same low level of contact resistivity using $\mathrm{Ag}$ instead of $\mathrm{Ag} / \mathrm{Al}$ pastes to contact $\mathrm{B}$ emitters with or without established surface passivation layers. ${ }^{14,15}$

All presented $\mathrm{SiO}_{\mathrm{x}}: \mathrm{B}$ and $\mathrm{SiN}_{\mathrm{x}}$ layers are deposited in a single chamber, inductively coupled plasma plasmaenhanced chemical vapor deposition (ICP-PECVD) lab-tool. The lab-tool displays direct as well as remote plasma characteristics for high-density films. The reaction gas mixture consists of $\mathrm{SiH}_{4}, \mathrm{CO}_{2}$, and $\mathrm{B}_{2} \mathrm{H}_{6}$ diluted in $\mathrm{H}_{2}$. Depending on the desired $\mathrm{B}$ doping profile, different gas flows and ratios are used to deposit the $\mathrm{SiO}_{\mathrm{x}}$ :B layers. $\mathrm{SiN}_{\mathrm{x}}$ layers, used as barrier layers, are deposited in the same vacuum step on top of the doping oxide. All high-temperature drive-in steps take place in a temperature range of $900-1050{ }^{\circ} \mathrm{C}$ for $1-2 \mathrm{~h}$ either in a $\mathrm{POCl}_{3}$ tube furnace in case of co-diffusion or in a 
dopant-free tube under nitrogen flow to avoid parasitic indiffusion of $\mathrm{P}$ for drive-in of uncapped or thinner films. After removal of the ICP-PECVD doping layer in aqueous HF, all reference samples are passivated by a stack consisting of $\mathrm{Al}_{2} \mathrm{O}_{3}$ using an atomic layer deposition tool (FlexAl from Oxford Instruments) and ICP-PECVD $\mathrm{SiN}_{\mathrm{x}}$ deposited on both sides and fired in a belt furnace under optimized firing conditions. All measurements are conducted on $250 \mu \mathrm{m}$ thick float-zone grown n-type Si substrates with base resistivity of $200 \Omega \mathrm{cm}$. Sheet resistance is measured using a four-point probe setup, doping profiles by an electro-chemical CV (ECV) setup, emitter saturation current density $\mathrm{j}_{0 \mathrm{E}}$ at a minority carrier density (MCD) of $5 \times 10^{15} \mathrm{~cm}^{-3}$, and implied open circuit voltage $\mathrm{iV}_{\mathrm{OC}}$ at 1 sun using a WCT-120 Sinton lifetime tester. The atomic B concentration in the dielectric layer is determined by ICP-OES (optical emission spectrometry) from Agilent Technologies. Scanning electron microscopy (SEM) imaging is carried out using a Zeiss Neon 40 EsB. Contact resistivity is determined using the transfer length method (TLM). Anti-reflective coating (ARC) relevant properties are measured by ellipsometry.

The B concentration in the BSG films was determined to $4-9 \times 10^{21} \mathrm{~cm}^{-3}$ depending on doping layer thickness and deposition parameters (e.g., gas flow ratio). The optical properties, such as absorption and reflection, are less affected by film thickness as they are by deposition parameters. An increase in $\mathrm{B}$ concentration shifts the refractive index of $\mathrm{SiO}_{\mathrm{x}}: \mathrm{B}$ from 1.5 to a maximum of 1.7 at $633 \mathrm{~nm}$ reachable with given maximum doping gas flow in the ICP-PECVD tool. The extinction coefficient is $<1 \times 10^{-4}$ in the range of $300-1200 \mathrm{~nm}$. The anti-reflective coating quality for random pyramid texture is evaluated maximizing the internal quantum efficiency and subsequently the theoretical short circuit current density $\mathrm{j}_{\mathrm{SC}, \mathrm{t}}$ using a standard model to calculate the relevant film parameters. ${ }^{16,17}$ In case of a BSG single layer, the optimal thickness calculated is $102 \mathrm{~nm}$ with a $\mathrm{j}_{\mathrm{SC}, \mathrm{t}}$ of $39.5 \mathrm{~mA} / \mathrm{cm}^{2}$. In comparison, the same cell model results in $39.7 \mathrm{~mA} / \mathrm{cm}^{2}$ for a single $\mathrm{SiN}_{\mathrm{x}}$ layer of $75 \mathrm{~nm}$ thickness with a refractive index of 2.0. Further optimization leads to a double anti-reflective coating layer with a stack of $\mathrm{SiO}_{\mathrm{x}}$ :B and $\mathrm{SiN}_{\mathrm{x}}$. In case of the aforementioned refractive index of 1.5 for $\mathrm{SiO}_{\mathrm{x}}$ :B and 2.0 for $\mathrm{SiN}_{\mathrm{x}}$, an optimal stack with increased short wavelength response can increase $j_{S C, t}$ to $40.0 \mathrm{~mA} / \mathrm{cm}^{2}$. The thickness for the two films is 76 and $57 \mathrm{~nm}$, respectively. Depending on the optical properties of the BSG layer, the $\mathrm{SiN}_{\mathrm{x}}$ layer therefore increases the anti-reflective properties for an improved ARC layer on cell level.

The doped area for application in solar cells is formed from the BSG in a drive-in step with a set temperature and duration. The $\mathrm{B}$ diffusion constant and subsequently the emitter depth thereby increase with temperature. The latter also increases with drive-in duration. Fig. 1 shows exemplarily different $\mathrm{B}$ doping profiles for most of the conceivable parameter variations. Beginning with an increase in drive-in duration at constant temperature and from the same doping layer $\left(40 \mathrm{~nm} \mathrm{SiO}_{\mathrm{x}}\right.$ :B capped with $\left.60 \mathrm{~nm} \mathrm{SiN}_{\mathrm{x}}\right)$, the depth increases from $0.65 \mu \mathrm{m}$ (orange) to $0.75 \mu \mathrm{m}$ (purple). An increase in $\mathrm{B}$ concentration due to an increase in $\mathrm{B}_{2} \mathrm{H}_{6}$ gas flow allows for even thinner layers resulting in the same doping profile (black profile). In this case, the drive-in step was

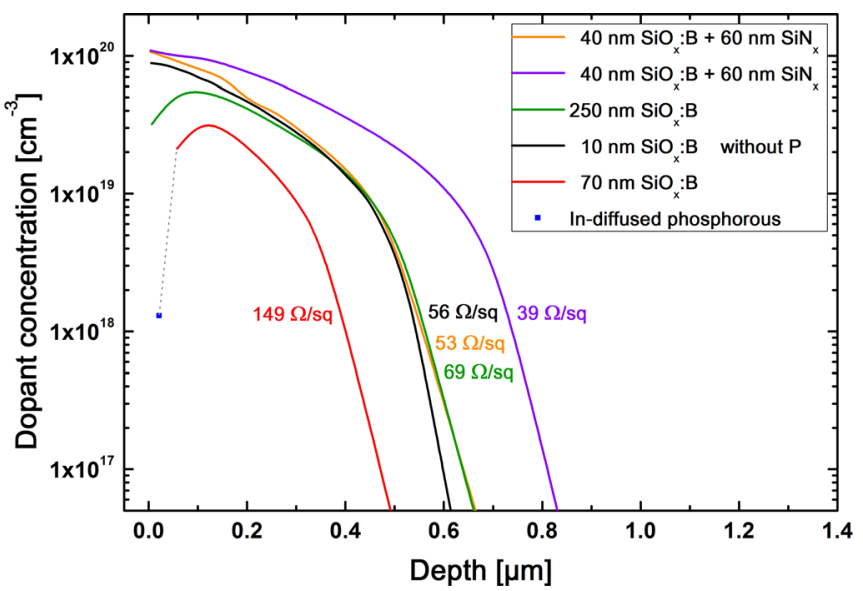

FIG. 1. Doping profiles of different B emitters from uncapped and capped doping layers with varying thickness, diffusion, and deposition parameters. The black profile was driven-in without $\mathrm{POCl}_{3}$ flow. The purple profile has a longer drive-in step than the orange one with the same doping layer stack.

performed in a nitrogen flow environment to prevent parasitic indiffusion of P. Co-diffusion can only be applied if the doping layer/stack is able to prevent $\mathrm{P}$ indiffusion, which, in our case, $\mathrm{SiO}_{\mathrm{x}}$ : $\mathrm{B}$ layers with less than $100 \mathrm{~nm}$ thickness (for drive-in temperature below $950^{\circ} \mathrm{C}$ ) do not. An example is the red doping profile that is depleted on the surface due to indiffused $\mathrm{P}$. This surface depletion is not to be mistaken for the depletion due to oxidation (e.g., in case of $\mathrm{BBr}_{3}$ diffusion) or the depletion due to a depleted source, as is the case for the green profile of a $250 \mathrm{~nm}$ thick BSG with lower B concentration. If the layer is a barrier (sufficiently thick BSG or capped by at least $20 \mathrm{~nm}$ thick $\mathrm{SiN}_{\mathrm{x}}{ }^{18}$ ) and the doping source is non-depleting regarding the drive-in parameters used, a surface doping concentration of up to $1 \times 10^{20} \mathrm{~cm}^{-3}$ is possible (black, orange, and purple profiles). This allows for a co-diffusion of B and P (n-type doped areas from gas phase and/or solid phase doping source). Surface concentration, sheet resistance, and profile depth allow for screenprinted contacts with low contact resistivity.

If uncapped BSG layers are used on planar or textured wafers to form B emitters, a complete and preferably pinholefree coverage of the surface by the layer during the diffusion step is necessary for both a homogeneous emitter thickness/ coverage as well as protection against parasitic $\mathrm{P}$ in-diffusion during co-diffusion. In all SEM images taken, the layers show no signs of pinholes and a sufficiently thick doping layer on textured samples. The film thickness (BSG) of about $0.1 \mu \mathrm{m}$ varies insignificantly on tip and edges of the pyramids in comparison to the sides or base (Fig. 2). Furthermore, the emitter formed underneath the doping layer follows the surface shape with a constant thickness (see $3 \mathrm{kV}$ part of the image). After in-diffusion, a layer with bright contrast (visible in the $5 \mathrm{kV}$ part of the image) forms between doping layer and emitter which is presumed to be a $\mathrm{B}$-depleted $\mathrm{SiO}_{\mathrm{x}}$ layer expected to be responsible for the high passivation quality.

Fig. 3 shows $j_{O E}$ and $i_{O C}$ of $B$ emitter samples passivated in three different ways: uncapped $\mathrm{SiO}_{\mathrm{x}}: \mathrm{B}$ as-diffused, $\mathrm{SiO}_{\mathrm{x}}: \mathrm{B} / \mathrm{SiN}_{\mathrm{x}}$ stack as-diffused and $\mathrm{Al}_{2} \mathrm{O}_{3} / \mathrm{SiN}_{\mathrm{x}}$ fired (reference). As the reference passivation stack is deposited on the same emitter samples after removal of the passivating BSG 


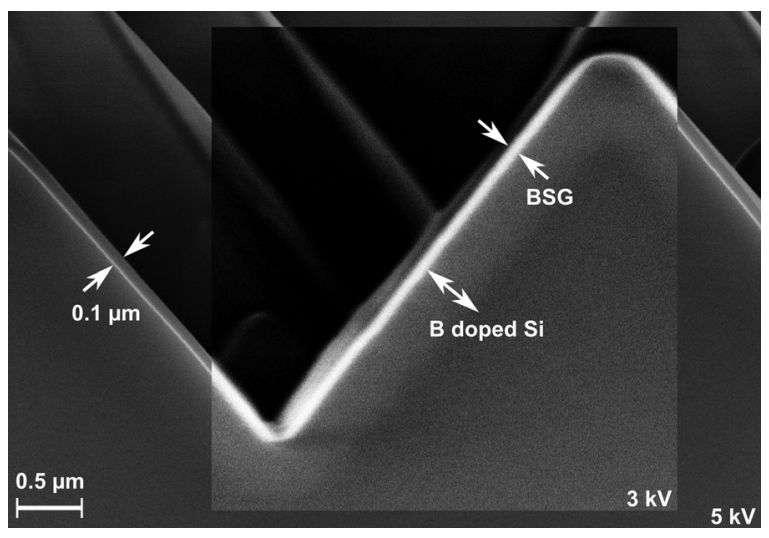

FIG. 2. SEM contrast image. Cross-section of a textured sample containing a $\mathrm{B}$ doping $\mathrm{SiO}_{\mathrm{x}}$ (BSG) with $0.1 \mu \mathrm{m}$ film thickness and homogeneously formed emitter (B doped $\mathrm{Si}$ ) with sheet resistance of $50 \Omega / \mathrm{sq}$ and junction depth of $0.6 \mu \mathrm{m}$.

layer, a direct comparison of the different passivation schemes is possible. The use of the uncapped doping layers (Fig. 3 left, $\mathrm{SiO}_{\mathrm{x}}$ :B) without $\mathrm{SiN}_{\mathrm{x}}$ capping layer leads to nearly as low $\mathrm{j}_{\mathrm{OE}}$ and high $\mathrm{iV}_{\mathrm{OC}}$ values as the subsequently applied reference passivation layer on the same samples (Fig. 2 right, $\mathrm{Al}_{2} \mathrm{O}_{3} / \mathrm{SiN}_{\mathrm{x}}$ ). As expected, the higher the sheet resistance, the lower the $\mathrm{j}_{\mathrm{OE}}$ and the higher the $\mathrm{iV}_{\mathrm{OC}}$ values. The passivation quality of the stack of $\mathrm{SiN}_{\mathrm{x}}$ capped BSG (Fig. 2 center, $\mathrm{SiO}_{\mathrm{x}}: \mathrm{B} / \mathrm{SiN}_{\mathrm{x}}$ ) leads to $\mathrm{iV}_{\mathrm{OC}}$ values of $\sim 675 \mathrm{mV}$ for 50-60 $\Omega / \mathrm{sq}$ emitters passivated with $\mathrm{SiO}_{\mathrm{x}}: \mathrm{B} / \mathrm{SiN}_{\mathrm{x}}$ layers, even surpassing the $\mathrm{Al}_{2} \mathrm{O}_{3} / \mathrm{SiN}_{\mathrm{x}}$ passivation layer commonly applied for $\mathrm{B}$ emitters. In this case, the $\mathrm{iV}_{\mathrm{OC}}$ at 1 sun is lowered despite the lower $\mathrm{j}_{\mathrm{OE}}$ value, because of the additional processing steps to apply the reference passivation stack and a possible subsequent bulk lifetime degradation.

The final aspect to be considered concerning application in high-efficiency solar cells is metal contact formation to the $\mathrm{B}$ emitter, which in our case was chosen to be screenprinting. $\mathrm{Ag} / \mathrm{Al}$ pastes are commonly used for this low-cost approach. The emitters presented here reach contact resistivity values below $1 \mathrm{~m} \Omega \mathrm{cm}^{2}$ with $\mathrm{Ag} / \mathrm{Al}$ pastes fired either through the doping layer (Fig. 4: 30 or $100 \mathrm{~nm}$ layer thickness) or the reference stack of $\mathrm{Al}_{2} \mathrm{O}_{3} / \mathrm{SiN}_{\mathrm{x}}$ at firing furnace

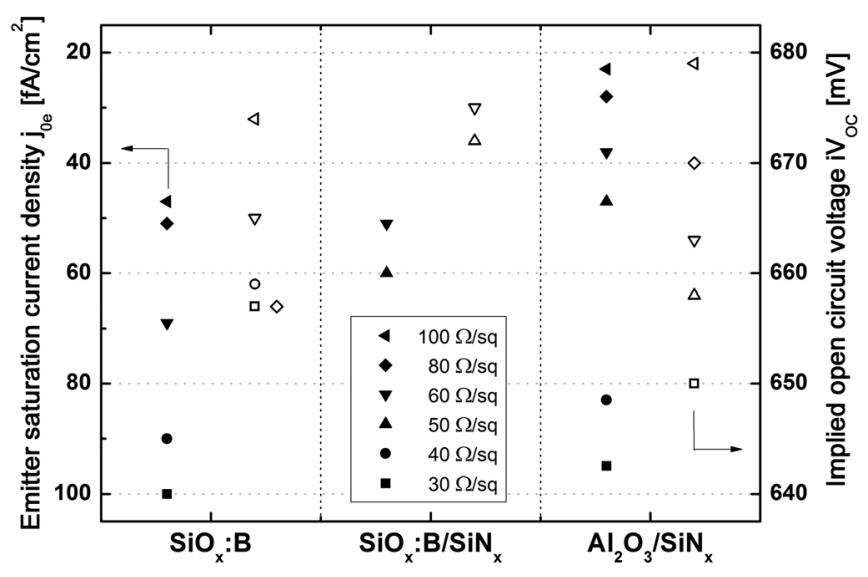

FIG. 3. joE (filled symbols; MCD of $5 \times 10^{15} \mathrm{~cm}^{-3}$ ) and $\mathrm{iV}_{\mathrm{OC}}$ (open symbols; at 1 sun) of $\mathrm{B}$ emitters with varying sheet resistance and passivation layer. The layers of the $\mathrm{SiO}_{\mathrm{x}}: \mathrm{B} / \mathrm{SiN}_{\mathrm{x}}$ stack have $40 \mathrm{~nm}$ and $60 \mathrm{~nm}$ thickness, respectively.

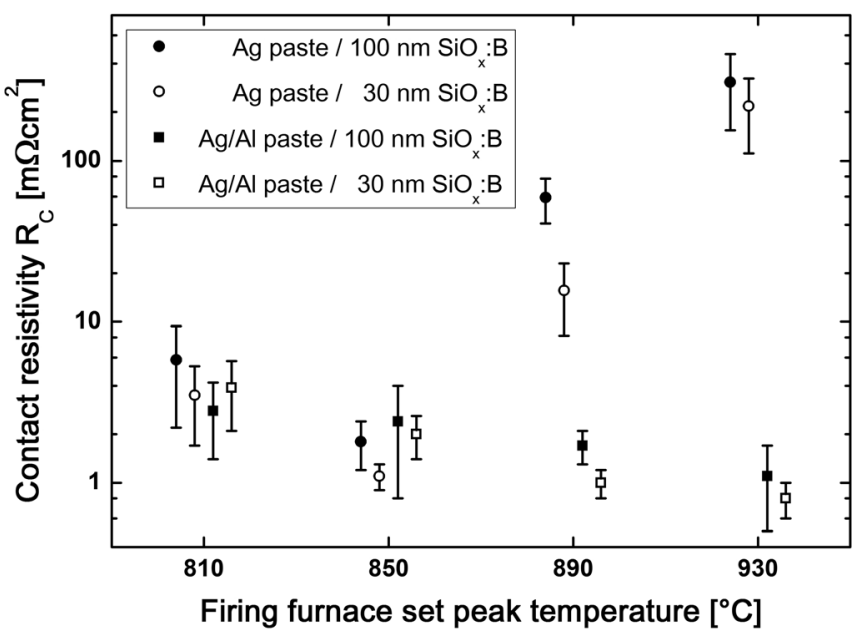

FIG. 4. Contact resistivity values of B emitters contacted by commercially available $\mathrm{Ag} / \mathrm{Al}$ (squares) and $\mathrm{Ag}$ (circles) pastes using $\mathrm{SiO}_{\mathrm{x}}: \mathrm{B}$ doping layers (30 and $100 \mathrm{~nm}$ thick films, open and filled symbols, respectively) in dependence of the firing furnace set peak temperature.

set peak temperatures of $850-930^{\circ} \mathrm{C}$. But, with the increase in firing temperature, the probability of shunting due to damage done to the space charge region using $\mathrm{Ag} / \mathrm{Al}$ paste increases. ${ }^{9,14}$ Since $\mathrm{Ag}$ pastes only lead to crystal growth near the surface, this kind of shunting problem does not occur in the same way. For higher temperatures, in contrast to the further decrease of contact resistivity by contact formation using $\mathrm{Ag} / \mathrm{Al}$ pastes, an increase in contact resistivity occurs for the Ag pastes. On B emitters, however, Ag pastes up to now never matched the low contact resistivity values of $\mathrm{Ag} / \mathrm{Al}$ pastes. With the support of $\mathrm{SiO}_{\mathrm{x}}: \mathrm{B}$ as passivation layer, it is now demonstrated that a $\mathrm{B}$ emitter can be contacted with commercially available Ag pastes with a contact resistivity value of around $1 \mathrm{~m} \Omega \mathrm{cm}^{2}$ for a firing temperature of $850^{\circ} \mathrm{C}$ (Fig. 4).

In this work, ICP-PECV-deposited $\mathrm{SiO}_{\mathrm{x}}$ doping layers were presented. They show that optical properties suitable for anti-reflective coating and passivation of the B doped crystalline $\mathrm{Si}$ surface act as a barrier against parasitic $\mathrm{P}$ in-diffusion during a co-diffusion step and support contact formation by screen-printing with Ag pastes. All these possibilities are combined within only one single layer/stack. An implied open circuit voltage of $675 \mathrm{mV}$ could be achieved, comparable to the reference $\mathrm{Al}_{2} \mathrm{O}_{3} / \mathrm{SiN}_{\mathrm{x}}$ : $\mathrm{H}$ passivation stack on the same emitter. The contact formation using this one doping layer allows for the use of Ag pastes for contacting B emitters with contact resistivity values of around $1 \mathrm{~m} \Omega \mathrm{cm}^{2}$. With a high flexibility regarding deposition parameters for the BSG layers and subsequently the B emitters, they are applicable to a variety of solar cell designs, i.e., n-PERT and IBC. Compared to former publications of multi-purpose BSG layers, we showed that our layers exceed the standard properties of doping source and passivation by additional contact formation support, optics, and barrier properties.

The authors would like to thank G. Fitzky, L. Mahlstädt and B. Rettenmaier for their support. Part of this work was financially supported by the German Federal Ministry for the Environment, Nature Conservation and Nuclear Safety 
(Grant No. FKZ 0325581). The content is the responsibility of the authors.

${ }^{1}$ C. S. Fuller and J. A. Ditzenberger, J. Appl. Phys. 25, 1439 (1954).

${ }^{2}$ A. Wang, J. Zhao, and M. A. Green, Appl. Phys. Lett. 57, 602 (1990).

${ }^{3}$ Y. Schiele, S. Fahr, S. Joos, G. Hahn, and B. Terheiden, Proceedings of the 28th EU PVSEC, Paris, France (James \& James (Science Publishers) Ltd., 2013), pp. 1242-1247.

${ }^{4}$ J. Armand, C. Oliver, B. Semmache, M. Gauthier, A. Foucaran, and Y. Cuminal, Proceedings of the 26th EU PVSEC, Hamburg, Germany (James \& James (Science Publishers) Ltd., 2011), pp. 1309-1312.

${ }^{5}$ P. Rothhardt, S. Meier, C. Demberger, A. Wolf, and D. Biro, Energy Proc. 55, 287 (2014).

${ }^{6}$ R. Keding, P. Rothhardt, C. Roters, A. Fallisch, S. Hohage, M. Hofmann, R. Woehl, D. Borchert, and D. Biro, Proceedings of the 27th EU PVSEC, Frankfurt, Germany (James \& James (Science Publishers) Ltd., 2012), pp. 1906-1911.

${ }^{7}$ N. Wehmeier, G. Schraps, H. Wagner, B. Lim, N.-P. Harder, and P. P. Altermatt, Proceedings of the 28th EU PVSEC, Paris, France (James \& James (Science Publishers) Ltd., 2013), pp. 1980-1984.

${ }^{8}$ J. Engelhardt, A. Frey, L. Mahlstaedt, S. Gloger, G. Hahn, and B. Terheiden, Energy Proc. 55, 235 (2014).
${ }^{9}$ A. Frey, J. Engelhardt, S. Fritz, S. Gloger, G. Hahn, and B. Terheiden, Proceedings of the 29th EU PVSEC, Amsterdam, Netherlands (James \& James (Science Publishers) Ltd., 2014), pp. 656-660.

${ }^{10}$ R. Keding, D. Stüwe, M. Kamp, C. Reichel, A. Wolf, R. Woehl, D. Borchert, H. Reinecke, and D. Biro, IEEE J. Photovoltaics 3(4), 1236 (2013).

${ }^{11}$ J. H. Ranzmeyer, Y. Schiele, G. Hahn, and B. Terheiden, Proceedings of the 28th EU PVSEC, Paris, France (James \& James (Science Publishers) Ltd., 2013), pp. 1367-1370.

${ }^{12}$ J. Seiffe, F. Pilath, D. Trogus, A. Brand, C. Savio, M. Hofmann, J. Rentsch, and R. Preu, IEEE J. Photovoltaics 3(1), 224 (2013).

${ }^{13}$ J. Seiffe, A. Gahoi, M. Hoffmann, J. Rentsch, and R. Preu, Phys. Status Solidi A 210(8), 1593 (2013).

${ }^{14}$ R. Lago, L. Pérez, H. Kerp, I. Freire, I. Hoces, N. Azkona, F. Recart, and J. C. Jimeno, Prog. Photovoltaics: Res. Appl. 18, 20 (2010).

${ }^{15}$ S. Fritz, S. Riegel, S. Gloger, D. Kohler, M. König, M. Hörtheis, and G. Hahn, Energy Proc. 38, 720 (2013).

${ }^{16} \mathrm{H}$. A. Macleod, Thin-Film Optical Filters (Institute of Physics Publications, Bristol, 1986).

${ }^{17}$ S. Baker-Finch and K. McIntosh, Prog. Photovoltaics: Res. Appl. 19, 406 (2011).

${ }^{18}$ J. Engelhardt, G. Hahn, and B. Terheiden, "Multifunctional ICP-PECVD silicon nitride layers for high-efficiency silicon solar cell applications," Energy Proc. (in press). 